\title{
Interference Impacts Working Memory in Mild Cognitive Impairment
}

\section{OPEN ACCESS}

Edited by:

Mark P. Burns,

Georgetown University, USA

Reviewed by:

Nelson Silva Filho,

Sao Paulo State University, Brazil

Zemin Wang,

Harvard Medical School, USA

${ }^{*}$ Correspondence:

Sara Aurtenetxe

sara.aurtenetxe@ctb.upm.es

Specialty section: This article was submitted to

Neurodegeneration,

a section of the journal

Frontiers in Neuroscience

Received: 19 June 2016 Accepted: 14 September 2016

Published: 13 October 2016

Citation:

Aurtenetxe S, García-Pacios J, del Río D, López ME, Pineda-Pardo JA,

Marcos A, Delgado Losada ML, López-Frutos JM and Maestú F (2016) Interference Impacts Working Memory in Mild Cognitive Impairment.

Front. Neurosci. 10:443. doi: 10.3389/fnins.2016.00443

\author{
Sara Aurtenetxe ${ }^{1 *}$, Javier García-Pacios ${ }^{1,2}$, David del Río ${ }^{1,3}$, María E. López ${ }^{1,4}$, \\ José A. Pineda-Pardo ${ }^{5,6}$, Alberto Marcos ${ }^{7}$, Maria L. Delgado Losada ${ }^{3,8}$, \\ José M. López-Frutos ${ }^{9}$ and Fernando Maestú ${ }^{1,3}$
}

\begin{abstract}
${ }^{1}$ Laboratory of Cognitive and Computational Neuroscience, Center for Biomedical Technology of Madrid (CBT), Universidad Complutense de Madrid and Universidad Politécnica de Madrid, Madrid, Spain, ${ }^{2}$ Department of Psychology, Faculty of Health Sciences, Camilo Jose Cela University, Madrid, Spain, ${ }^{3}$ Department of Basic Psychology II (Cognitive Processes), Universidad Complutense de Madrid, Madrid, Spain, ${ }^{4}$ Laboratory of Neuropsychology, Universitat de les Illes Balears, Palma de Mallorca, Spain, ${ }^{5}$ Centro Integral de Neurociencias AC, HM Puerta del Sur, Hospitales de Madrid Mostoles, Madrid, Spain, ${ }^{6}$ CEU San Pablo University, Madrid, Spain, ${ }^{7}$ Department of Neurology, San Carlos University Hospital, Madrid, Spain, ${ }^{8}$ Seniors Centre of the District of Chamartín, Madrid, Spain, ${ }^{9}$ Department of Basic Psychology, Universidad Autónoma de Madrid, Madrid, Spain
\end{abstract}

Mild cognitive impairment $(\mathrm{MCl})$ is considered a transitional stage between healthy aging and dementia, specifically Alzheimer's disease (AD). The most common cognitive impairment of $\mathrm{MCl}$ includes episodic memory loss and difficulties in working memory (WM). Interference can deplete WM, and an optimal WM performance requires an effective control of attentional resources between the memoranda and the incoming stimuli. Difficulties in handling interference lead to forgetting. However, the interplay between interference and $\mathrm{WM}$ in $\mathrm{MCl}$ is not well-understood and needs further investigation. The current study investigated the effect of interference during a WM task in $20 \mathrm{MCls}$ and 20 healthy elder volunteers. Participants performed a delayed match-to-sample paradigm which consisted in two interference conditions, distraction and interruption, and one control condition without any interference. Results evidenced a disproportionate impact of interference on the WM performance of MCls, mainly in the presence of interruption. These findings demonstrate that interference, and more precisely interruption, is an important proxy for memory-related deficits in $\mathrm{MCl}$. Thus, the current findings reveal novel evidence regarding the causes of WM forgetting in $\mathrm{MCl}$ patients, associated with difficulties in the mechanisms of attentional control.

Keywords: mild cognitive impairment, working memory, interference, behavioral research, aging

\section{INTRODUCTION}

Mild cognitive impairment (MCI) is considered a transitional stage between healthy aging and dementia, specifically Alzheimer's disease (AD). The most common clinical symptom of MCI is episodic memory loss, with a particularly rapid rate of forgetting and impaired delayed recall. However, deficits in working memory (WM) and executive functions are frequently observed in MCI populations as well (Albert et al., 2001; Huntley and Howard, 2010); specially in multidomain subtype (Klekociuk and Summers, 2014). WM is affected by interference, and its optimal performance requires adequate executive mechanisms to control attention between the to-beremembered stimuli and the interference (Sakai et al., 2002a,b). Difficulties in inhibitory control and attentional switching result in WM depletion in healthy aging (Clapp and Gazzaley, 2012). However, evidence on how interference my affect WM in MCI individuals is scarce and merits further investigation. 
The inhibitory model proposed by Hasher and Zacks (1988) postulates that changes in the ability to ignore or control distracting information underlie cognitive deficits in aging. Indeed, increasing evidence correlates age-related memory decay with reduced ability to regulate interference (Zacks and Hasher, 1994; Hasher et al., 1999; Jonides et al., 2000; Hedden and Park, 2001; Darowski et al., 2008; Healey et al., 2008; Stevens et al., 2008). Two main categories of interference have been mostly explored in aging research: distraction and interruption (Solesio-Jofre et al., 2011; Clapp and Gazzaley, 2012). Distraction refers to irrelevant stimuli which need to be ignored (e.g., ignoring an alarm while calculating the expenses). Interruption refers to stimuli which demand additional processing as a secondary task (also considered multitasking, e.g., switchingoff an alarm while calculating the expenses; Salvucci and Taatgen, 2008). Both stimuli share behavioral attributes because they both affect WM performance, but differ in the degree of impact (interruption has a greater impact on WM than distraction) and also in the underlying mechanisms that support them (Clapp and Gazzaley, 2012). Although both types of interference are handled by top-down process, distraction requires a controlled suppression/inhibition of the irrelevant stimulus, while interruption requires in addition a controlled attention switching mechanism. Based on this evidence, it becomes important to disentangle between these two categories of interference when studying the mechanisms responsible for WM depletion in MCI.

WM difficulties in MCIs have been observed through neuropsychological assessments (Saunders and Summers, 2010; see Huntley and Howard, 2010, for a neuropsychological review about early $\mathrm{AD}$ profiles) and experimental paradigms (Belleville et al., 2007, 2008a; Missonnier et al., 2007; Kochan et al., 2011). In addition, difficulties in inhibition, attention/task-switching and in resolving interference have been also evidenced through experimental procedures (Albert et al., 2001; Wylie et al., 2007; Belleville et al., 2008b; Bélanger and Belleville, 2009; Borkowska et al., 2009; Lonie et al., 2009; Sinai et al., 2010; Clément et al., 2012). In this line, several studies have evidenced that memory consolidation in MCI individuals is significantly affected by difficulties in memory control from interference (Della Sala et al., 2005; Dewar et al., 2009, 2012). For example, results from California verbal learning-like tests reflect the vulnerability to semantic interference in MCI patients, being a predictive factor of conversion to AD (Loewenstein et al., 2007; Rabin et al., 2009; Silva et al., 2012). Besides, the negative impact of interference has been also observed during short memory delay periods. Deiber et al. (2011) explored the neuronal response to distraction during WM in single- and multi-domain MCI patients. Results showed altered mechanisms for controlling distraction especially in the multi-domain subgroup of patients. In a similar manner, AlescioLautier et al. (2007) and Belleville et al. (2007) observed memory difficulties when dividing attention between a memory probe and an interfering stimulus in MCIs. Furthermore, those patients with more severe clinical status revealed greater vulnerability to interference. Based on the above mentioned studies, it becomes important to assess the impact of external stimuli when evaluating memory abilities in MCI populations. However, as far as we are aware of, there is no evidence showing how distraction and interruption differently affect WM performance within the same MCI individuals. Therefore, the present study aimed to explore the effect of two types of interference on WM in MCI and healthy elderly participants. We employed a visual delayed match-to-sample task with three conditions: non-interference, distraction and interruption. Under these circumstances, we expected: (a) reduced WM in all conditions in the MCI sample, and (b) higher impact of interruption than distraction on WM performance, especially in the MCI group.

\section{METHODS}

\section{Participants}

A total of 40 volunteers were included in the study. All of the participants were over 65 years of age, right-handed (Oldfield, 1971) and native Spanish speakers. The participants were divided into two groups based on their clinical profiles: $20 \mathrm{MCI}$ patients and 20 healthy elderly controls. The groups were matched for age; educational level and gender (see Table 1). MCI patients were recruited from the Hospital Universitario San Carlos, and control adult volunteers were recruited from the Seniors Center of the district of Chamartín, Madrid.

\section{Diagnostic Criteria}

All of the participants were rated with a variety of standardized diagnostic instruments that included the following: the Spanish version of the mini-mental state examination, MMSE (Lobo et al., 1979), the Geriatric Depression Scale (GDS-15; Yesavage et al., 1982), the Global Deterioration Scale (GDS; Reisberg et al., 1982), the Hachinski Ischemic Score (HIS; Rosen et al., 1980), the Functional assessment questionnaire (FAQ; Pfeffer et al., 1982), and the questionnaire for Instrumental Activities of Daily Living (IADL; Lawton and Brody, 1969).

MCI diagnosis was established according to the National Institute on Aging-Alzheimer Association (NIA-AA) criteria (Albert et al., 2011): (1) self- or informant-reported cognitive complaint; (2) objective evidence of impairment in one or more cognitive domains; (3) preserved independence in functional abilities; and (4) not demented (McKhann et al., 2011). Besides meeting the core clinical criteria for MCI, subjects showed a positive biomarker reflecting neuronal injury (hippocampal volume reduction) which was measured by MRI (see Figure 1). So, the MCI group could be categorized as MCI attributable to AD-intermediate likelihood.

All subjects underwent an extensive neuropsychological assessment to evaluate their cognitive status in multiple areas with the following tests: clock drawing test (Agrell and Dehlin, 1998), direct and inverse digit span test [Wechsler Memory Scale (WMS-III); Wechsler, 1987], immediate and delayed recall (WMS-III; Wechsler, 1987), phonemic and semantic fluency (controlled oral word association test; Benton and Hamsher, 1989), ideomotor apraxis of Barcelona test (Peña-Casanova, 1990), rule shift cards (behavioral assessment of the dysexecutive syndrome; Norris and Tate, 2000), visual object and space perception test (VOSP; Warrington and James, 1991), Boston 
TABLE 1 | Demography and neuropsychology data (mean scores and standard deviation in parenthesis) are shown for controls (CNT) and MCI patients.

\begin{tabular}{|c|c|c|c|c|c|c|c|c|c|c|c|c|c|c|}
\hline & $\mathbf{N}$ & Left $\mathrm{HV}^{*}$ & Right HV* & Age & Sex & MMSE* & Education & GDS & FAQ & GDS-15 & & & & \\
\hline CNT & 20 & $2.5(0.4) \times 10^{-3}$ & $2.5(0.3) \times 10^{-3}$ & $71.7(2.8)$ & $12 \mathrm{~F}, 8 \mathrm{M}$ & $29.4(0.7)$ & $3.7(1.0)$ & $1.0(0.0)$ & $0.05(0.2)$ & $2.2(4.0)$ & & & & \\
\hline \multirow[t]{2}{*}{$\mathrm{MCl}$} & 20 & $2.1(0.4) \times 10^{-3}$ & $2.1(0.4) \times 10^{-3}$ & $73.6(3.5)$ & $9 F, 11 M$ & $28.3(1.7)$ & $3.0(1.2)$ & $3.0(0.0)$ & $0.8(1.5)$ & $2.0(2.4)$ & & & & \\
\hline & LM-I* & LM-II* & FD* & BD* & CDT-0* & CDT-C* & FAS-F* & FAS-S* & TMT-A & TMT-B & Cards* & BNT* $^{*}$ & VOSP & Apraxis \\
\hline CNT & $40.3(8.4)$ & $26.5(7.9)$ & $8.9(2.7)$ & $6.0(2.0)$ & $7.0(0.0)$ & $7.0(0.0)$ & $15.2(3.9)$ & $17.3(3.7)$ & $23.8(0.9)$ & 21.2 (3.3) & $3.3(1.0)$ & 55.9 (3.9) & $9.3(2.9)$ & $7.9(0.2)$ \\
\hline $\mathrm{MCl}$ & $20.3(11.3)$ & $8.5(8.7)$ & $6.4(1.5)$ & $4.7(1.1)$ & $6.0(1.6)$ & $6.2(1.7)$ & $10.8(3.2)$ & $12.9(2.8)$ & $22.6(5.6)$ & $18.2(7.8)$ & $2.3(1.4)$ & $51.3(7.5)$ & $8.5(3.6)$ & $7.2(1.9)$ \\
\hline
\end{tabular}

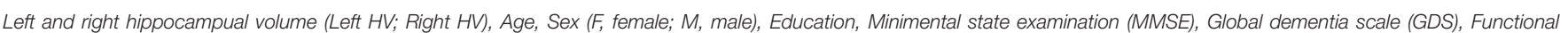

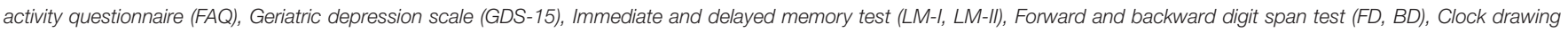

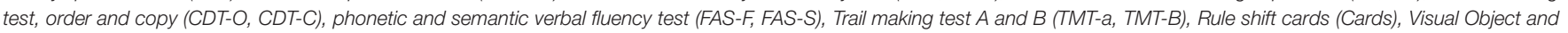
Space Perception Test (VOSP), and Ideomotor apraxis test (Apraxis).

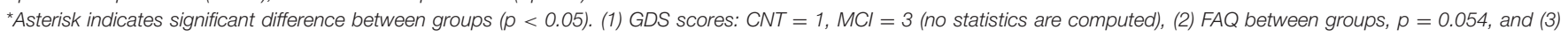
CDT-C between groups, $p=0.05$.

naming test (Kaplan et al., 1983), and trail-making tests A and B (Reitan, 1958).

According to their clinical and neuropsychological profile patients were diagnosed as amnesic-multidomain MCI (Petersen, 2004).

Other inclusion criteria were the absence of significant cerebral-vascular disease (i.e., modified Hachinski score $\leq$ 4) or depressive symptomatology (i.e., GDS-15 score $\leq 5$ ). The participants were not using drugs that could affect cognitive performance (including cholinesterase inhibitors). All participants were free of significant medical, neurologic and/or psychiatric diseases other than MCI.

Prior to the study, all of the participants gave a written informed consent to participate in the investigation. The study was approved by the local ethics committee.

\section{Hippocampal Volumes}

Hippocampal volumes were measured as anatomical evidences of brain atrophy characteristic for MCI and AD (Albert et al., 2011; McKhann et al., 2011). For most of the subjects included in this paper (15 MCIs and 10 controls), a T1-weighted MRI was available, acquired in a GE Healthcare 1.5 Tesla magnetic resonance scanner, using a high-resolution antenna, and a homogenization pure filter (fast spoiled gradient echo sequence; repetition time, $11.2 \mathrm{~ms}$; echo time, $4.2 \mathrm{~ms}$; inversion time, $450 \mathrm{~ms}$; flip angle, $12^{\circ} ; 1 \mathrm{~mm}$ slice thickness; $256 \times 256$ matrix; and field of view, $25 \mathrm{~cm}$ ). These MRI images were processed with Freesurfer software (version 5.1.0) and its specialized tool for automated cortical and subcortical segmentation (Fischl et al., 2002) to obtain the volume of several brain areas, including hippocampus. Finally, volumes were normalized with respect to the individual intracranial volume (ICV) to account for differences in head volume over subjects.

\section{Stimuli}

Trial-unique neutral, anonymous male and female faces across a large age range were used as stimuli in the current experiment. The hair and ears were removed digitally to avoid non-facespecific cues. The experiment was computerized through Eprime1.2 software (Psychology Software Tools, Inc.).

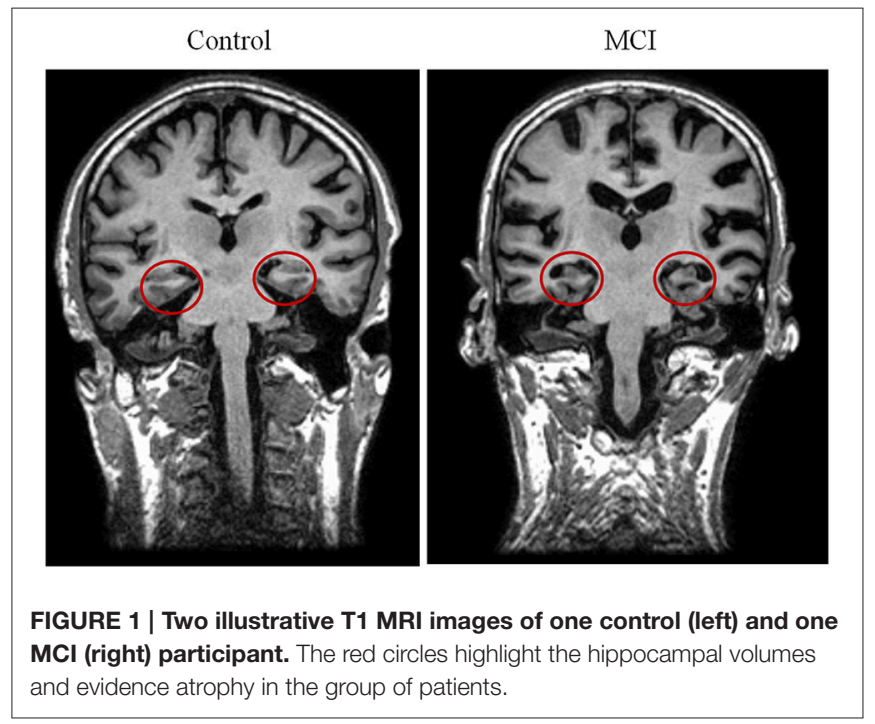

\section{Experimental Paradigm}

The participants performed a delayed match-to-sample task with three conditions: non-interference (NI), distraction (DIS), and interruption (INT; see Figure 2 for a representation of the paradigm). According to previous aging studies using very similar tasks (Solesio-Jofre et al., 2011; Clapp and Gazzaley, 2012) each condition was presented in a block. Each block consisted of 32 randomly presented trials resulting in a total of 96 trials per participant. The block presentation order was counterbalanced across subjects.

Before the experiment, participants were instructed about the task and also carried out a practice session to ensure an adequate understanding. All of the conditions consisted of three main phases: encoding, maintenance, and recognition. In the encoding phase, a face was displayed for a $1000 \mathrm{~ms}$ period and the participants were instructed to encode it. In the maintenance period, the participants were instructed to keep the encoded face in mind for a $4000 \mathrm{~ms}$ delay period. In the recognition phase, a single face was displayed for $1000 \mathrm{~ms}$. Participants were 


\section{Working memory task}

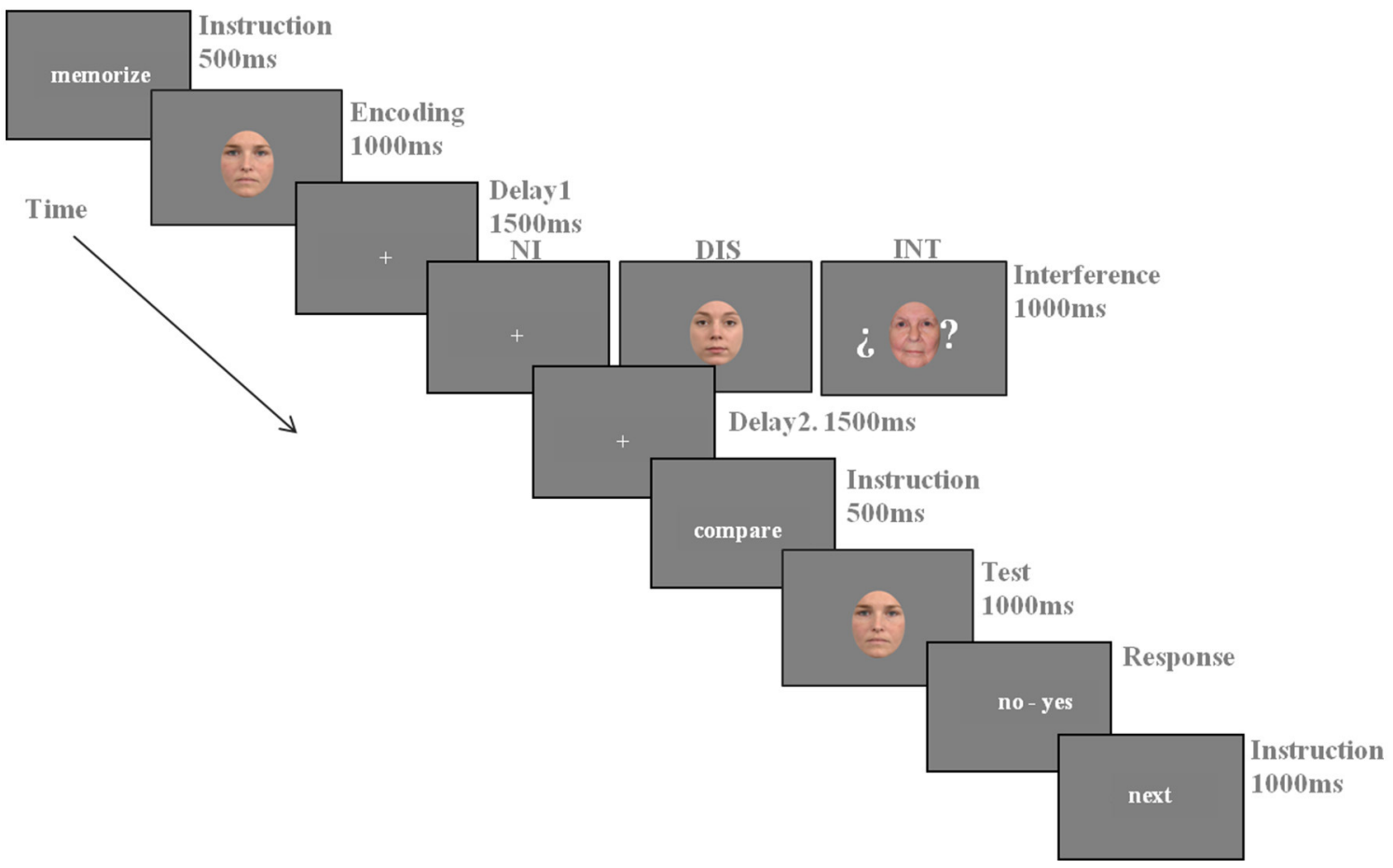

FIGURE 2 | The working memory task consisted of three conditions: Non-Interference (NI), Distraction (DIS), and Interruption (INT). All of the conditions were structured in three main phases: encoding, delay and recognition (See Experimental Paradigm section for details).

instructed to make a match/non-match button press as rapidly as possible, without sacrificing accuracy, to indicate if the face was the same as the one presented in the encoding phase. To ensure that all of the participants got enough time to respond, a response slide ("no-yes") was displayed after the recognition phase and maintained until the participant made the button press. This response slide was followed by the instruction "next" for $500 \mathrm{~ms}$, which indicated the step to the next trial. Both the encoding and retrieval phases were preceded by the instructions "memorize" and "compare" for $500 \mathrm{~ms}$ each, respectively, to ensure adequate orientation within each phase of the task. The instruction regarding the maintenance phase varied between the conditions, depending on the presence or not of a distraction or interruption stimulus. In the NI condition, a fixation cross was displayed in the center of the screen for the $4000 \mathrm{~ms}$ of maintenance period, and the participants were instructed to keep the encoded face in mind during this period. In the DIS condition, a face stimulus was added as a distractor for $1000 \mathrm{~ms}$ after the first $1500 \mathrm{~ms}$ of the maintenance period. The participants were instructed to ignore the distractor while continuing to focus on the computer screen during the presentation of the distractor, and while maintaining the encoded face. The INT condition included a face stimulus as an interruption after the encoding phase, which was displayed for $1000 \mathrm{~ms}$ after the first $1500 \mathrm{~ms}$ of the maintenance period. The participants were instructed to make a button press if the interruption face was judged to be over
60 years of age. If not, they did not press any button. The interrupting face was presented between two question marks, indicating the additional requirement to process and respond to the stimulus. All participants responded to the interruption face with a minimum of $75 \%$ of correct responses.

\section{Statistical Analysis}

The neuropsychological scores were compared between healthy and MCI groups by means of independent sample $t$-tests.

The analysis of the WM task was based on correct responses for each condition and group. The statistical analysis of the accuracy and reaction time (RT) was performed by means of twoway repeated measures ANCOVA using a within-group factor of condition (NI, DIS, and INT), a between-group factor of diagnosis (controls and MCIs) and the FAQ scores as covariable (given a trend toward significance between the groups. See Table 1). The resulting $p$-values of pairwise comparisons were corrected using the Bonferroni procedure.

To further examine the differential impact of interference on WM performance (accuracy and RT), the scores regarding the DIS and INT conditions were normalized to the performance of the NI condition. Thus, the effect of distraction and interruption was calculated for each group using $\mathrm{Z}$ scores: Effect of Interference $=$ mean $[(I-X) / S E]$, where $I$ was the accuracy/reaction time during DIS or INT for each participant and $X$ and $S D$ were the mean and standard error values of each group for NI. Once 
the $\mathrm{Z}$ scores were calculated, independent sample $t$-tests were performed to examine potential differences between the groups.

\section{RESULTS}

\section{Neuropsychology}

Analysis of the demographic and neuropsychological data revealed significant lower scores in the MCI group, compared with the control group, as indicated by asterisks in Table 1.

\section{Working Memory Accuracy}

See Figure 3A for accuracy data. Mauchly's test indicated that the assumption of sphericity had not been violated $\left[\chi_{(2)}^{2}=0.8\right.$, $\mathrm{p}=0.67]$. Analysis of the accuracy resulted in a main effect of diagnosis $\left[F_{(1,33)}=16.19 ; p<0.001 ; \eta^{2}=0.33\right]$, with lower performance in MCIs than in controls. Also, a main effect of condition was revealed $\left[F_{(2,66)}=30.04 ; p<0.001 ; \eta^{2}=0.54\right]$, such that all participants showed the greatest accuracy in the NI condition, reduction in accuracy in the DIS, and the lower accuracy during the INT condition. In addition, a significant two-way interaction of condition $\mathrm{x}$ diagnosis $\left[F_{(2,66)}=5.5\right.$; $\left.p<0.005 ; \eta^{2}=0.14\right]$ was observed.

Within-group comparisons revealed a reduction in accuracy by distraction and interruption in the two groups (all $p<$ 0.05). Furthermore, interruption elicited a greater impact than distraction in the group of patients $(p<0.001)$ but not in controls $(p>0.05)$. Comparisons between groups revealed lower performance in MCI patients across the three conditions (all $p<0.05)$.

\section{Reaction Time}

See Figure 3B for reaction time data. Mauchly's test indicated that the assumption of sphericity had been violated $\left[\chi_{(2)}^{2}=11.23, p=\right.$ 0.004 ] and therefore, degrees of freedom were corrected using Greenhouse-Geisser estimates of sphericity $(\varepsilon=0.77)$. Analysis of the RTs resulted in a main effect of diagnosis $\left[F_{(1,33)}=8.88\right.$; $p<0.01 ; \eta^{2}=0.21$, with slower RTs in MCIs than in controls; and a main effect of condition $\left[F_{(2,66)}=7.4 ; p<0.005 ; \eta^{2}=\right.$ 0.18 , where all participants showed the largest RTs in the INT condition, intermediate RTs in the DIS and the fastest RTs in the NI condition. Additionally, data revealed a trend toward a twoway interaction of condition $\times$ diagnosis $\left[F_{(2,66)}=3.29 p=0.057\right.$; $\left.\eta^{2}=0.091\right]$.

\section{Effect of Interference on Accuracy between Groups}

This analysis showed a disproportionate accuracy depletion by interruption in patients comparing with controls [Effectinterruption; $t_{(38)}=2.1, p<0.05$ ]. In contrast, no significant differences were observed between groups regarding distraction [Effect-distraction; $\left.t_{(38)}=0.1, p>0.1\right]$.

\section{Effect of Interference on Reaction Time between Groups}

This analysis revealed no significant differences in RT between groups neither by distraction [Effect-distraction; $t_{(38)}=0.5$, $p>0.1]$, nor by interruption [Effect-interruption; $t_{(38)}=1.6$, $p>0.1]$.

\section{DISCUSSION}

The current study explored the effect of two types of interference, distraction and interruption, during the performance of a visual WM task in MCI patients and healthy elder volunteers. Results showed that interference affected WM (Clapp et al., 2010) in both populations but in a different manner. While both MCI and control participants were similarly affected by distraction, MCI patients were disproportionately affected by interruption. These results show novel evidence for the negative impact of interference on WM in individuals with MCI.

The neuropathology of MCI has been largely observed in medial lobe structures, such as the hippocampus (Hyman et al., 1984; Tabert et al., 2006). In accordance, its clinical symptomatology has been most frequently described as an impaired ability to maintain and retrieve information from memory (Welsh et al., 1992; Petersen et al., 1999). Our results support this evidence by showing significantly reduced hippocampal volume (bilaterally), and reduced immediate and delayed recall of information in traditional episodic memory task (WMS-III) in patients when compared with controls.

In addition, our data are consistent with previous studies reporting difficulties to maintain information during short time periods in MCIs (Alescio-Lautier et al., 2007; Belleville et al., 2007; Kessels et al., 2010; Gagnon and Belleville, 2011). Nevertheless, the current experimental task tries to go one step beyond by evaluating how the WM retention ability in MCI is further affected by external stimuli. In agreement with the current results, both distraction and interruption have been associated with decrements in WM due to aging (Clapp and Gazzaley, 2012). However, the main results of the current study reveal, a WM vulnerability to distraction and interruption and a high susceptibility to the last in MCI patients. These results are in accordance with the neuropsychological profiles showing a dysexecutive profile in this group of amnesic-multidomain MCI individuals. Executive processing, including control of interference, relies on the prefrontal cortex (PFC) and on its interplay with posterior regions of the brain (Miller and Cohen, 2001). In this line, in addition to the involvement of the medial temporal lobe structures in the cognitive profile of patients with MCI (Petersen et al., 2006), affection of prefrontal regions are evident as well. Amyloid deposition, volume changes, altered activation, and connections of the $\mathrm{PFC}$ with other brain regions are some of the features of MCIs (Bell-McGinty et al., 2005; Maestú et al., 2008; Chao et al., 2009; Okello et al., 2009; Bajo et al., 2010). This evidence explains why impairments in executive processing, especially in inhibition, are often observed in the clinical profile of MCI (Wylie et al., 2007; Bélanger and Belleville, 2009; see Johns et al., 2012 for a review), and also in AD (Collette et al., 1999, 2009; Amieva et al., 2004; Belleville et al., 2007). Indeed, changes in the structure and function of the PFC in individuals with MCI (especially in multi-domain) have been specially related with alterations in executive control 


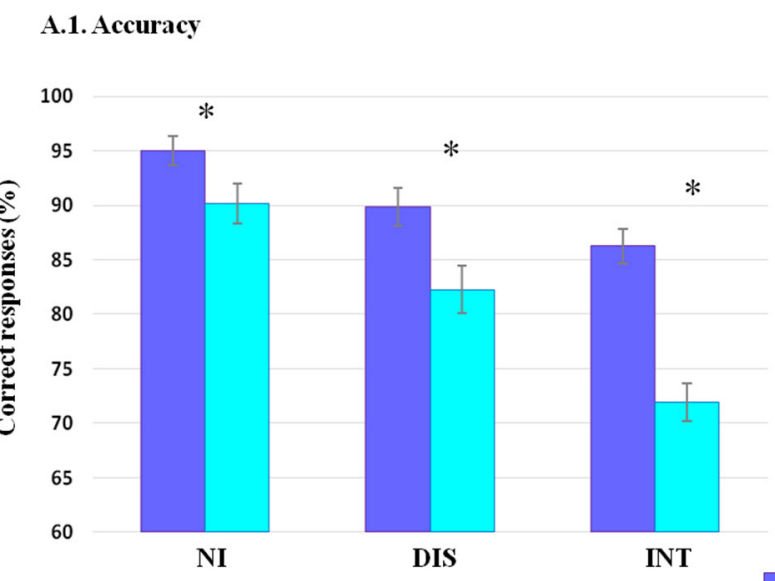

\section{B.1. Reaction time}

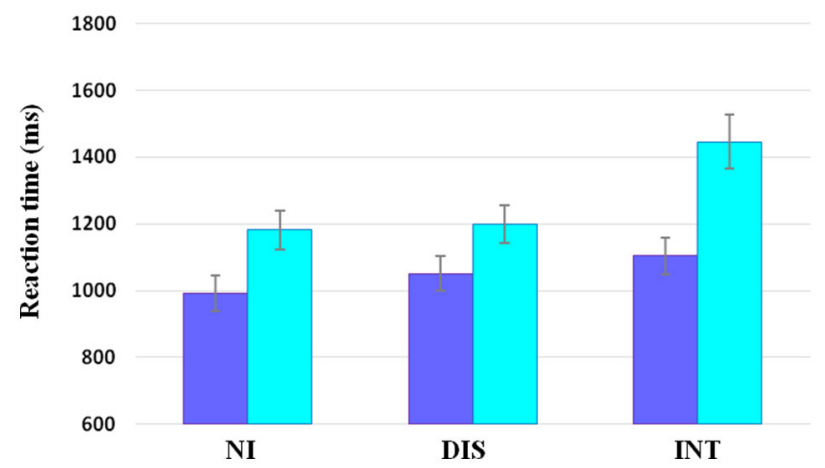

A.2. Effects on accuracy

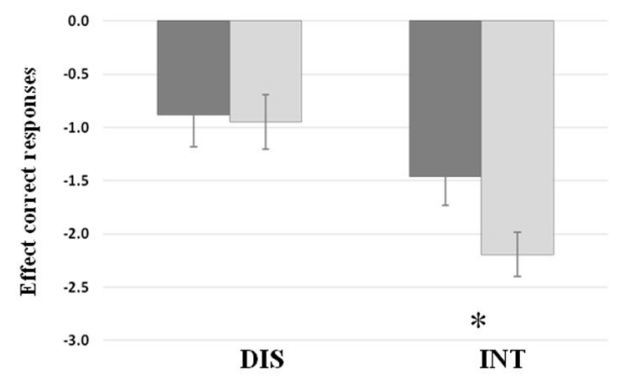

CNT

$\mathrm{MCl}$

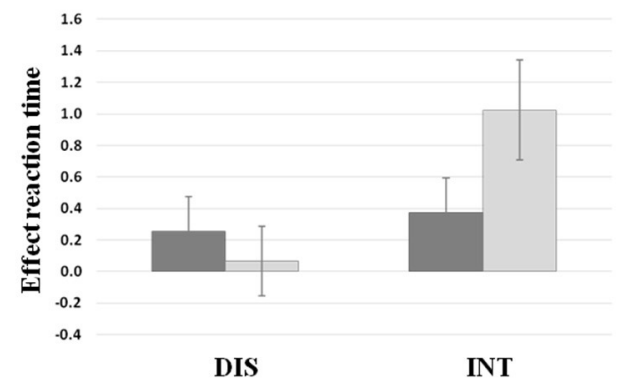

FIGURE 3 | Results for accuracy and reaction time (RT) are shown. The percentage of correct responses (A.1) and RT in milliseconds (B.1) are shown for each condition (non-interference, NI, distraction, DIS, and interruption, INT) in each group (controls, CNT, dark blue, and MCls in light blue). The effects of interference on accuracy (A.2) and RTs (B.2) are shown for distraction (DIS) and for interruption (INT) in each group (controls, CNT, in dark gray and MCls in light gray). Error bars denote standard error of the mean. Statistical analysis of the accuracy revealed main effect of diagnosis and condition $(p<0.001)$, and a condition $\times$ group interaction $(p<0.005)$. The effect of interruption on accuracy was significantly greater in patients than with controls $(p<0.05)$. Reaction times showed main effect of diagnosis and condition $(p<0.001)$. *indicates significant difference between groups $(p<0.05)$.

skills (Grambaite et al., 2011; Zheng et al., 2014). These evidences suggest that alterations in the PFC of our MCI individuals might underlie altered mechanisms to control interference and in consequence, lead to forgetting in WM.

In an attempt to explore the neural patterns of the control of distraction during WM in amnesic-multi-domain MCIs, Deiber et al. (2011) explored the electroencephalographic (EEG) activity of such a population while they performed a WM task. The experimental design included two faces and two letter stimuli presented in an interspersed manner. The stimuli had to be encoded or suppressed depending on the instructions before each trial. The results revealed reduced right central alpha frequency synchronization in response to distracting letters in the MCI group compared to the controls. Authors concluded that this hypo-synchronization reflected altered mechanisms of suppressing irrelevant stimuli. These results support the current data showing that WM depletion in MCI patients is exacerbated by an alteration to inhibit irrelevant stimuli.
Regarding interruption, our results show that even when both groups present larger latencies to perform the INT condition, the accuracy of the MCIs becomes disproportionately affected in this condition (confirmed by the Effect on interruption). These data evidence a special susceptibility of MCI individuals to maintain memoranda in the presence of stimuli that require additional processing resources. Previous research reveals difficulties in MCIs when attempt to perform two tasks simultaneously (Albert et al., 2001; Belleville et al., 2008b; Borkowska et al., 2009; Lonie et al., 2009; Sinai et al., 2010; Clément et al., 2012). Belleville et al. (2007) studied attentional control skills in MCI patients under three experimental tasks. The most significant results were found within a modified version of the Brown-Peterson procedure (Morris, 1986). In such a task, information is maintained over short delays while a second task (completing addition) is performed. The results showed that attention to the secondary task affects memory performance in MCI. Furthermore, memory accuracy was related to overall severity suggesting a gradual 
decline of memory and interference resolution in the continuum to AD. In a similar study, Alescio-Lautier et al. (2007) evaluated the memory recognition abilities of $\mathrm{MCI}$ and $\mathrm{AD}$ patients during delay periods that were interference-free or filled by a secondary task (interruption). Both groups of patients showed WM depletion in the presence of interference. In accordance with their results, the current data claim to an affection of WM when engaging and disengaging attention between interference and memoranda.

From the current data, a strong claim about the neural mechanisms that underlie WM affection by interruption is not straightforward. Nevertheless, evidence shows the involvement of the PFC in the top-down control of attention over posterior regions of the brain (Miller and Cohen, 2001). On the one hand, handling distraction during WM requires attentional and inhibitory control mechanisms which allow maintaining the relevant information and voluntarily inhibiting the irrelevant (Hedden and Park, 2001). On the other hand, handling interruption during WM requires, in addition, attention switching abilities which allow handling attention between the memoranda and the secondary task (Sakai et al., 2002a,b; Clapp et al., 2011). Altogether, it seems reasonable that the WM depletion of MCIs might be highlighted by difficulties in inhibition and in switching attention between stimuli, probably caused by alterations in the PFC and/or in the prefrontal-posterior network of the brain. Empirical evidence about the role of this brain network in WM abilities in MCIs should be addressed in future neurophysiological studies.

One limitation of the current study was that not all the hippocampal volumes were accessible. However, given that statistical significance was observed using $75 \%$ of the patients and $50 \%$ of the controls, similar results to the current ones will be expected when comparing the data from all the participants. A

\section{REFERENCES}

Agrell, B., and Dehlin, O. (1998). The clock-drawing test. Age Ageing 27, 399-403. doi: 10.1093/ageing/27.3.399

Albert, M. S., DeKosky, S. T., Dickson, D., Dubois, B., Feldman, H. H., Fox, N. C., et al. (2011). The diagnosis of mild cognitive impairment due to Alzheimer's disease: recommendations from the National Institute on Aging-Alzheimer's Association workgroups on diagnostic guidelines for Alzheimer's disease. Alzheimers Dement. 7, 270-279. doi: 10.1016/j.jalz.2011. 03.008

Albert, M. S., Moss, M. B., Tanzi, R., and Jones, K. (2001). Preclinical prediction of AD using neuropsychological tests. J. Int. Neuropsychol. Soc. 7, 631-639. doi: 10.1017/S1355617701755105

Alescio-Lautier, B., Michel, B. F., Herrera, C., Elahmadi, A., Chambon, C., Touzet, C., et al. (2007). Visual and visuospatial shortterm memory in mild cognitive impairment and Alzheimer disease: role of attention. Neuropsychologia 45, 1948-1960. doi: 10.1016/j.neuropsychologia.2006.04.033

Amieva, H., Phillips, L. H., Della Sala, S., and Henry, J. D. (2004). Inhibitory functioning in Alzheimer's disease. Brain 127, 949-964. doi: 10.1093/brain/awh045

Bajo, R., Maestú, F., Nevado, A., Sancho, M., Gutiérrez, R., Campo, P., et al. (2010). Functional connectivity in mild cognitive impairment during a memory task: implications for the disconnection hypothesis. J. Alzheimers Dis. 22, 183-193. doi: 10.3233/JAD-2010-100177 second limitation of the current investigation refers to the effect size of the condition $\times$ group interaction. Increasing the number of participants in future studies will confirm the present findings.

In sum, the current study indicates that difficulties in suppressing distraction and switching attention between memoranda and external stimuli play a fundamental role in WM performance in amnesic-multidomain MCI patients, and that these failures are modulated by the cognitive demands of interference. Thus, the disproportionate vulnerability of MCI patients to a high demanding interference condition points to its relevance when assessing WM ability in this clinical population. Given the high amount of relevant and irrelevant information in our daily living activities, future research should keep investigating the relation between the attentional control and WM mechanisms that contribute to forgetting in MCI patients.

\section{AUTHOR CONTRIBUTIONS}

Design of the experiment: SA, JG, JF, FM, ML. Acquisition of data: SA Analysis of data SA, JG, DD, JP. Clinical evaluation of participants: AM, MD. Interpretation of data and Drafting of manuscript: SA, JG, DD, ML, FM.

\section{ACKNOWLEDGMENTS}

This work was supported by a predoctoral fellowship from the Basque Government to SA, by a postdoctoral fellowship (FJCI2014-22730) to ML, and by the PSI2009-14415-C03 project of the Spanish Ministry of Science and Innovation" and PSI201238375-C03-01 project of the Spanish Ministry of Economy. Authors would like to thank Cristina Fernández for assistance in the analysis and Bizitzen Fundazioa and especially M.A. and B.A. for assistance and support in piloting.

Bélanger, S., and Belleville, S. (2009). Semantic inhibition impairment in mild cognitive impairment:distinctive feature of upcoming cognitive decline? Neuropsychology 23, 592-606. doi: 10.1037/a0016152

Belleville, S., Bherer, L., Lepage, E., Chertkow, H., and Gauthier, S. (2008b). Task switching capacities in persons with Alzheimer's disease and mild cognitive impairment. Neuropsychologia 46, 2225-2233. doi: 10.1016/j.neuropsychologia.2008.02.012

Belleville, S., Chertkow, H., and Gauthier, S. (2007). Working Memory and control of attention in persons with Alzheimer's disease and mild cognitive impairment. Neuropsychology 21, 458-469. doi: 10.1037/0894-4105.21.4.458

Belleville, S., Sylvain-Roy, S., de Boysson, C., and Ménard, M. C. (2008a). Characterizing the memory changes in persons with mild cognitive impairment. Prog. Brain Res. 169, 365-375. doi: 10.1016/S0079-6123(07)0 0023-4

Bell-McGinty, S., Lopez, O. L., Meltzer, C. C., Scanlon, J. M., Whyte, E. M., Dekosky, S. T., et al. (2005). Differential cortical atrophy in subgroups of mild cognitive impairment. Arch. Neurol. 62, 1393-1397. doi: 10.1001/archneur.62.9.1393

Benton, A. L., and Hamsher, K. (1989). Multilingual Aplasia Examination, 2nd Edn. Iowa City, IA: AJA Associates.

Borkowska, A., Drozdz, W., Jurkowski, P., and Rybakowski, J. K. (2009). The Wisconsin Card Sorting Test and the N-back test in mild cognitive impairment and elderly depression. World J. Biol. Psychiatry 10, 870-876. doi: $10.1080 / 15622970701557985$ 
Chao, L. L., Pa, J., Duarte, A., Schuff, N., Weiner, M. W., Kramer, J. H., et al. (2009). Patterns of cerebral hypoperfusion in amnestic and dysexecutive MCI. Alzheimer Dis. Assoc. Disord. 23, 245-252. doi: 10.1097/WAD.0b013e318199ff46

Clapp, W. C., and Gazzaley, A. (2012). Distinct mechanisms for the impact of distraction and interruption on working memory in aging. Neurobiol. Aging 33, 134-148. doi: 10.1016/j.neurobiolaging.2010.01.012

Clapp, W. C., Rubens, M. T., Gazzaley, A. (2010). Mechanisms of working memory disruption by external interference. Cereb. Cortex 20, 859-872. doi: 10.1093/cercor/bhp150

Clapp, W. C., Rubens, M. T., Sabharwal, J., and Gazzaley, A. (2011). Deficit in switching between functional brain networks underlies the impact of multitasking on working memory in older adults. Proc. Natl. Acad. Sci. U.S.A. 108, 7212-7217. doi: 10.1073/pnas. 1015297108

Clément, F., Gauthier, S., and Belleville, S. (2012). Executive functions in mild cognitive impairment: emergence and breakdown of neural plasticity. Cortex 49, 1268-1279. doi: 10.1016/j.cortex.2012.06.004

Collette, F., Schmidt, C., Scherrer, C., Adam, S., and Salmon, E. (2009). Specificity of inhibitory deficits in normal aging and Alzheimer's disease. Neurobiol. Aging 30, 875-889. doi: 10.1016/j.neurobiolaging.2007.09.007

Collette, F., Van der Linden, M., Bechet, S., and Salmon, E. (1999). Phonological loop and central executive functioning in Alzheimer's disease. Neuropsychologia 37, 905-918. doi: 10.1016/S0028-3932(98)00148-1

Darowski, E., Helder, E., and Zacks, R. (2008). Age-related differences in cognition: the role of distraction control. Neuropsychology 5, 638-644. doi: 10.1037/08944105.22.5.638

Deiber, M. P., Ibáñez, V., Herrmann, F., Rodriguez, C., Emch, J., Missonnier, P., et al. (2011). Face short-term memory-related electroencephalographic patterns can differentiate multi- versus single-domain amnestic mild cognitive impairment. J. Alzheimers Dis. 26, 157-169. doi: 10.3233/JAD-2011-110170

Della Sala, S., Cowan, N., Beschin, N., and Perini, M. (2005). Just lying there, remembering: improving recall of prose in amnesic patients with mild cognitive impairment by minimising interference. Memory 13, 435-440. doi: 10.1080/09658210344000387

Dewar, M., Garcia, Y. F., Cowan, N., and Della Sala, S. (2009). Delaying interference enhances memory consolidation in amnesic patients. Neuropsychology 23, 627-634. doi: 10.1037/a0015568

Dewar, M., Pesallaccia, M., Cowan, N., Provinciali, L., and Della Sala, S. (2012). Insights into spared memory capacity in amnestic MCI and Alzheimer's disease via minimal interference. Brain Cogn. 78, 189-199. doi: 10.1016/j.bandc.2011.12.005

Fischl, B., Salat, D. H., Busa, E., Albert, M., Dieterich, M., Haselgrove, C., et al. (2002). Whole brain segmentation: automated labeling of neuroanatomical structures in the human brain. Neuron 33, 341-355. doi: 10.1016/S08966273(02)00569-X

Gagnon, L. G., and Belleville, S. (2011). Working memory in mild cognitive impairment and Alzheimer's disease: contribution of forgetting and predictive value of complex span tasks. Neuropsychology 25, 226-236. doi: $10.1037 / \mathrm{a} 0020919$

Grambaite, R., Selnes, P., Reinvang, I., Aarsland, D., Hessen, E., Gjerstad, L., et al. (2011). Executive dysfunction in mild cognitive impairment is associated with changes in frontal and cingulate white matter tracts. J. Alzheimers Dis. 27, 453-462. doi: 10.3233/JAD-2011-110290

Hasher, L., and Zacks, R. T. (1988). Working memory, comprehension, and aging: A review and a new view. Psychol. Learn. Motiv. 22, 193-225. doi: 10.1016/S0079-7421(08)60041-9

Hasher, L., Zacks, R. T., and May, C. P. (1999). "Inhibitory control, circadian arousal, and age," in Attention and Performance, XVII, Cognitive Regulation of Performance: Interaction of Theory and Application, eds D. Gopher and A. Koriat (Cambridge, MA: MIT Press), 653-675.

Healey, M. K., Campbell, K. L., and Hasher, L. (2008). Cognitive aging and increased distractibility: costs and potential benefits. Prog. Brain Res. 169, 353-363. doi: 10.1016/s0079-6123(07)00022-2

Hedden, T., and Park, D. (2001). Aging and interference in verbal working memory. Psychol. Aging 4, 666-681. doi: 10.1037/0882-7974.16.4.666

Huntley, J. D., and Howard, R. J. (2010). Working memory in early Alzheimer's disease: a neuropsychological review. Int. J. Geriatr. Psychiatry 25, 121-132. doi: $10.1002 /$ gps. 2314
Hyman, B. T., Van Hoesen, G. W., Damasio, A. R., and Barnes, C. L. (1984). Alzheimer's disease: cell-specific pathology isolates the hippocampal formation. Science 225, 1168-1170. doi: 10.1126/science.6474172

Johns, E. K., Phillips, N. A., Belleville, S., Goupil, D., Babins, L., Kelner, N., et al. (2012). The profile of executive functioning in amnestic mild cognitive impairment: disproportionate deficits in inhibitory control. J. Int. Neuropsychol. Soc. 18, 541-555. doi: 10.1017/s1355617712000069

Jonides, J., Marshuetz, C., Smith, E. E., Reuter-Lorenz, P. A., Koeppe, R. A., and Hartley, A. (2000). Age differences in behavior and PET activation reveal differences in interference resolution in verbal working memory. J. Cogn. Neurosci. 12, 188-196. doi: 10.1162/089892900561823

Kaplan, E., Goodglass, H., and Weintraub, S. (1983). The Boston Naming Test. Philadelphia, PA: Lea and Febiger.

Kessels, R. P., Meulenbroek, O., Fernández, G., and Olde Rikkert, M. G. (2010) Spatial working memory in aging and mild cognitive impairment: effects of task load and contextual cueing. Neuropsychol. Dev. Cogn. B Aging Neuropsychol. Cogn. 17, 556-574. doi: 10.1080/13825585.2010.481354

Klekociuk, S. J., and Summers, M. J. (2014). Lowered performance in working memory and attentional sub-processes are most prominent in multidomainamnestic mild cognitive impairment subtypes. Psychogeriatrics 14, 63-71. doi: 10.1111/psyg. 12042

Kochan, N. A., Breakspear, M., Valenzuela, M., Slavin, M. J., Brodaty, H., Wen, W., et al. (2011). Cortical responses to graded working memory challenge predict functional decline in mild cognitive impairment. Biol. Psychiatry 70, 123-130. doi: 10.1016/j.biopsych.2011.03.006

Lawton, M. P., and Brody, E. M. (1969). Assessment of older people: selfmaintaining and instrumental activities of daily living. Gerontologist 9, 179-186. doi: 10.1093/geront/9.3_Part_1.179

Lobo, A., Ezquerra, J., Gómez Burgada, F., Sala, J. M., and Seva Díaz, A. (1979). Cognocitive mini-test (a simple practical test to detect intellectual changes in medical patients). Actas Luso Esp. Neurol. Psiquiatr. Cienc. Afines 7, 189-202.

Loewenstein, D. A., Acevedo, A., Agron, J., and Duara, R. (2007). Vulnerability to proactive semantic interference and progression to dementia among older adults with mild cognitive impairment. Dement. Geriatr. Cogn. Disord. 24, 363-368. doi: 10.1159/000109151

Lonie, J. A., Tierney, K. M., Herrmann, L. L., Donaghey, C., O’Carroll, R. E., Lee, A., et al. (2009). Dual task performance in early Alzheimer's disease, amnestic mild cognitive impairment and depression. Psychol. Med. 39, 23-31. doi: 10.1017/S0033291708003346

Maestú, F., Campo, P., Del Río, D., Moratti, S., Gil-Gregorio, P., Fernández, A., et al. (2008). Increased biomagnetic activity in the ventral pathway in mild cognitive impairment. Clin. Neurophysiol. 119, 1320-1327. doi: 10.1016/j.clinph.2008.01.105

McKhann, G. M., Knopman, D. S., Chertkow, H., Hyman, B. T., Jack, C. R. Jr., Kawas, C. H., et al. (2011). The diagnosis of dementia due to Alzheimer's disease: recommendations from the National Institute on Aging-Alzheimer's Association workgroups on diagnostic guidelines for Alzheimer's disease. Alzheimers Dement. 7, 263-269. doi: 10.1016/j.jalz.2011.03.005

Miller, E. K., and Cohen, J. D. (2001). An integrative theory of prefrontal cortex function. Annu. Rev. Neurosci. 24, 167-202. doi: 10.1146/annurev.neuro.24.1.167

Missonnier, P., Deiber, M. P., Gold, G., Herrmann, F. R., Millet, P., Michon, A., et al. (2007). Working memory load-related electroencephalographic parameters can differentiate progressive from stable mild cognitive impairment. Neuroscience 150, 346-356. doi: 10.1016/j.neuroscience.2007.09.009

Morris, R. G. (1986). Short-term forgetting in senile dementia of the Alzheimer's type. Cogn. Neuropsychol. 3, 77-97. doi: 10.1080/02643298608252670

Norris, G., and Tate, R. L. (2000). The behavioural assessment of the dysexecutive syndrome (BADS): ecological, concurrent and construct validity. Neuropsychol. Rehabil. 10, 33-45. doi: 10.1080/096020100389282

Okello, A., Koivunen, J., Edison, P., Archer, H. A., Turkheimer, F. E., Nagren, K., et al. (2009). Conversion of amyloid positive and negative MCI to AD over 3 years: an 11C-PIB PET study. Neurology 73, 754-760. doi: 10.1212/WNL.0b013e3181b23564

Oldfield, R. C. (1971). The assessment and analysis of handedness: the Edinburgh inventory. Neuropsychologia 9, 97-113. doi: 10.1016/0028-3932(71)90067-4 
Peña-Casanova, J. (1990). Programa Integrado de Exploración NeuropsicológicaTest Barcelona Protocolo, Masson, S.A., Barcelona.

Petersen, R. C. (2004). Mild cognitive impairment as a diagnostic entity. J. Int. Med. 256, 183-194. doi: 10.1111/j.1365-2796.2004.01388.x

Petersen, R. C., Parisi, J. E., Dickson, D. W., Johnson, K. A., Knopman, D. S., Boeve, B. F., et al. (2006). Neuropathologic features of amnestic mild cognitive impairment. Arch. Neurol. 63, 665-672. doi: 10.1001/archneur.63.5.665

Petersen, R. C., Smith, G. E., Waring, S. C., Ivnik, R. J., Tangalos, E. G., and Kokmen (1999). Mild cognitive impairment: clinical characterization and outcome. Arch. Neurol. 56, 303-308. doi: 10.1001/archneur.56.3.303

Pfeffer, R. I., Kurosaki, T. T., Harrah C. H. Jr., Chance, J. M., and Filos, S. (1982). Measurement of functional activities in older adults in the community. J. Gerontol. 37, 323-329. doi: 10.1093/geronj/37.3.323

Rabin, L. A., Paré, N., Saykin, A. J., Brown, M. J., Wishart, H. A., Flashman, L. A., et al. (2009). Differential memory test sensitivity for diagnosing amnestic mild cognitive impairment and predicting conversionto Alzheimer's disease. Neuropsychol. Dev. Cogn. B Aging Neuropsychol. Cogn. 16, 357-376. doi: $10.1080 / 13825580902825220$

Reisberg, B., Ferris, S. H., de Leon, M. J., and Crook, T. (1982). The Global Deterioration Scale for assessment of primary degenerative dementia. Am. J. Psychiatry 139, 1136-1139. doi: 10.1176/ajp.139.9.1136

Reitan, R. M. (1958). Validity of the Trail Making test as an indicator of organic brain damage. Percept. Mot. Skills 8, 271-276. doi: 10.2466/pms.1958.8.3.271

Rosen, W. G., Terry, R. D., Fuld, P. A., Katzman, R., and Peck, A. (1980). Pathological verification of ischemic score in differentiation of dementias. Ann. Neurol. 7, 486-488. doi: 10.1002/ana.410070516

Sakai, K., Rowe, J. B., and Passingham, R. E. (2002a). Parahippocampal reactivation signal at retrieval after interruption of rehearsal. J. Neurosci. 22, 6315-6320.

Sakai, K., Rowe, J. B., and Passingham, R. E. (2002b). Active maintenance in prefrontal area 46 creates distractor-resistant memory. Nat. Neurosci. 5, 479-484. doi: 10.1038/nn846

Salvucci, D. D., and Taatgen, N. A. (2008). Threaded cognition: an integrated theory of concurrent multitasking. Psychol. Rev. 115, 101-130. doi: 10.1037/0033-295X.115.1.101

Saunders, N. L., and Summers, M. J. (2010). Attention and working memory deficits in mild cognitive impairment. J. Clin. Exp. Neuropsychol. 32, 350-357. doi: 10.1080/13803390903042379

Silva, D., Guerreiro, M., Maroco, J., Santana, I., Rodrigues, A., Bravo Marques, J., et al. (2012). Comparison of four verbal memory tests for the diagnosis and predictive value of mild cognitive impairment. Dement. Geriatr. Cogn. Dis. Extra 2, 120-131. doi: 10.1159/000336224

Sinai, M., Phillips, N. A., Chertkow, H., and Kabani, N. J. (2010). Task switching performance reveals heterogeneity amongst patients with mild cognitive impairment. Neuropsychology 24, 757-774. doi: 10.1037/a0020314

Solesio-Jofre, E., Lorenzo-López, L., Gutiérrez, R., López-Frutos, J. M., RuizVargas, J. M., and Maestú, F. (2011). Age effects on retroactive interference during working memory maintenance. Biol. Psychol. 88, 72-82. doi: 10.1016/j.biopsycho.2011.06.011

Stevens, W. D., Hasher, L., Chiew, K. S., and Grady, C. L. (2008). A neural mechanism underlying memory failure in older adults. J. Neurosci. 28, 12820-12824. doi: 10.1523/JNEUROSCI.2622-08.2008

Tabert, M. H., Manly, J. J., Liu, X., Pelton, G. H., Rosenblum, S., Jacobs, M., et al. (2006). Neuropsychological prediction of conversion to Alzheimer disease in patients with mild cognitive impairment. Arch. Gen. Psychiatry 63, 916-924. doi: 10.1001/archpsyc.63.8.916

Warrington, E. K., and James, M. (1991). The Visual Object and Space Perception Battery. Bury St. Edmunds: Thames Valley Test Company.

Wechsler, D. (1987). Wechsler Memory Scale-Revised (Manual). San Antonio, TX: The Psychological Corporation.

Welsh, K. A., Butters, N., Hughes, J. P., Mohs, R. C., and Heyman, A. (1992). Detection and staging of dementia in Alzheimer's disease. Use of the neuropsychological measures developed for the Consortium to Establish a Registry for Alzheimer's Disease. Arch. Neurol. 49, 48-52. doi: 10.1001/archneur.1992.00530290030008

Wylie, S. A., Ridderinkhof, K. R., Eckerle, M. K., and Manning, C. A. (2007) Inefficient response inhibition in individuals with mild cognitive impairment. Neuropsychologia 45, 1408-1419. doi: 10.1016/j.neuropsychologia.2006. 11.003

Yesavage, J. A., Brink, T. L., Rose, T. L., Lum, O., Huang, V., Adey, M., et al. (1982). Development and validation of a geriatric depression screening scale: a preliminary report. J. Psychiatr. Res. 17, 37-49. doi: 10.1016/00223956(82)90033-4

Zacks, R. T., and Hasher, L. (1994). "Directed ignoring: inhibitory regulation of working memory," in Inhibitory Mechanisms in Attention, Memory, and Language eds D. Dagenbach and T. H. Carr (New York, NY: Academic Press), 241-264.

Zheng, D., Sun, H., Dong, X., Liu, B., Xu, Y., Chen, S., et al. (2014). Executive dysfunction and gray matter atrophy in amnestic mild cognitive impairment. Neurobiol. Aging 35, 548-555. doi: 10.1016/j.neurobiolaging.2013.09.007

Conflict of Interest Statement: The authors declare that the research was conducted in the absence of any commercial or financial relationships that could be construed as a potential conflict of interest.

Copyright () 2016 Aurtenetxe, García-Pacios, del Río, López, Pineda-Pardo, Marcos, Delgado Losada, López-Frutos and Maestú. This is an open-access article distributed under the terms of the Creative Commons Attribution License (CC BY). The use, distribution or reproduction in other forums is permitted, provided the original author(s) or licensor are credited and that the original publication in this journal is cited, in accordance with accepted academic practice. No use, distribution or reproduction is permitted which does not comply with these terms. 